\title{
Discovery and development of novel DNA-PK inhibitors by targeting the unique Ku-DNA interaction
}

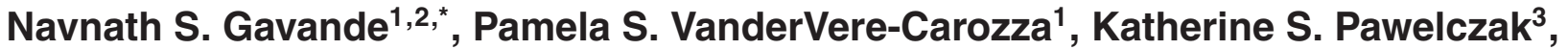 \\ Pamela Mendoza-Munoz ${ }^{1}$, Tyler L. Vernon ${ }^{1}$, Leslyn A. Hanakahi ${ }^{4}$, Matthew Summerlin ${ }^{4}$, \\ Joseph R. Dynlacht ${ }^{5}$, Annabelle H. Farmer ${ }^{1}$, Catherine R. Sears ${ }^{1}$, Nawar Al Nasrallah ${ }^{1}$, \\ Joy Garrett ${ }^{5}$ and John J. Turchi ${ }^{\oplus 1,3,6,{ }^{*}}$
}

\begin{abstract}
${ }^{1}$ Department of Medicine, Indiana University School of Medicine, Indianapolis IN 46202, USA, ${ }^{2}$ Department of Pharmaceutical Sciences, Wayne State University College of Pharmacy and Health Sciences, Detroit, MI 48201, USA, ${ }^{3}$ NERx Biosciences, 212 W 10th St. Suite A480, Indianapolis, IN 46202, USA, ${ }^{4}$ Department of Biopharmaceutical Sciences, University of Illinois College of Pharmacy, Rockford, IL 61107, USA, ${ }^{5}$ Department of Radiation Oncology, Indiana University School of Medicine, Indianapolis, IN 46202, USA and ${ }^{6}$ Department of Biochemistry and Molecular Biology, Indiana University School of Medicine, Indianapolis, IN 46202, USA
\end{abstract}

Received July 30, 2020; Revised October 02, 2020; Editorial Decision October 05, 2020; Accepted October 09, 2020

\section{ABSTRACT}

DNA-dependent protein kinase (DNA-PK) plays a critical role in the non-homologous end joining (NHEJ) repair pathway and the DNA damage response (DDR). DNA-PK has therefore been pursued for the development of anti-cancer therapeutics in combination with ionizing radiation (IR). We report the discovery of a new class of DNA-PK inhibitors that act via a novel mechanism of action, inhibition of the Ku-DNA interaction. We have developed a series of highly potent and specific Ku-DNA binding inhibitors (Ku-DBi's) that block the Ku-DNA interaction and inhibit DNAPK kinase activity. Ku-DBi's directly interact with the $\mathrm{Ku}$ and inhibit in vitro NHEJ, cellular NHEJ, and potentiate the cellular activity of radiomimetic agents and IR. Analysis of Ku-null cells demonstrates that Ku-DBi's cellular activity is a direct result of $\mathrm{Ku}$ inhibition, as Ku-null cells are insensitive to Ku-DBi's. The utility of Ku-DBi's was also revealed in a CRISPR gene-editing model where we demonstrate that the efficiency of gene insertion events was increased in cells pre-treated with Ku-DBi's, consistent with inhibition of NHEJ and activation of homologous recombination to facilitate gene insertion. These data demonstrate the discovery and application of new series of compounds that modulate DNA repair pathways via a unique mechanism of action.

\section{INTRODUCTION}

DNA-PK, a serine/threonine protein kinase, is a member of the PI-3 kinase-related-kinase (PIKK) superfamily (1). The DNA-PK holoenzyme consists of the $469 \mathrm{kDa}$ catalytic subunit, DNA-PKcs and the Ku 70/80 DNA-binding complex. DNA-PKcs and $\mathrm{Ku} 70 / 80$ are involved in multiple pathways of DNA metabolism that could impact the development and treatment response of tumors, NHEJ, DDR and telomere stability (2). DNA-PK is required for NHEJcatalyzed repair of DSBs (3). Following the induction of a DSB, the Ku protein binds to the DNA termini; this is followed by DNA-PKcs binding. Auto-phosphorylation of DNA-PKcs and phosphorylation of other target proteins requires assembly of the DNA-PKcs-Ku complex at the DNA terminus that promotes processing, DNA-PK dissociation and the eventual association of the DNA-ligase IV/XRCC4/XLF complex to catalyze the final end-joining repair reaction. DNA-PK also participates in the larger DNA damage response (DDR). In this capacity, it can phosphorylate ATM and other downstream targets as well as be phosphorylated by ATM and ATR. This collective response ensures cells can respond to all types of DNA damage to promote survival. Inhibition of the DDR is being pursued with small molecule inhibitors developed to target nearly every kinase in the pathway. In addition, the $\mathrm{Ku}$ protein has been localized to telomeres where it is protects the chromosome termini. While the exact mechanisms of protection are still being elucidated, current models include protection from nuclease-catalyzed end degradation and more recently, blocking telomere excision and/or recombination (4). Importantly, the impact on telomeres is $\mathrm{Ku}$-specific and is independent of DNA-PKes $(5,6)$. Telom-

\footnotetext{
*To whom correspondence should be addressed. Tel: +1 317278 1996; Fax: +1 317274 0396; Email: jturchi@iu.edu Correspondence may also be addressed to Navnath S. Gavande. Tel: +1 313577 1523; Fax: +1 313577 2033; Email: ngavande@wayne.edu

(C) The Author(s) 2020. Published by Oxford University Press on behalf of Nucleic Acids Research.

This is an Open Access article distributed under the terms of the Creative Commons Attribution Non-Commercial License

(http://creativecommons.org/licenses/by-nc/4.0/), which permits non-commercial re-use, distribution, and reproduction in any medium, provided the original work is properly cited. For commercial re-use, please contact journals.permissions@oup.com
} 
ere maintenance may therefore be expected to be differentially impacted by Ku inhibitors versus DNA-PKcs targeted agents.

DNA-PK is dysregulated in many cancers, and tumors become reliant on increased DNA-PK activity to respond to the genomic instability associated with unregulated cancer cell growth (7-9). The enhanced ability of tumor cells to repair DSBs is also a major contributor to chemo- and radiotherapy resistance. Thus, blocking DNA-PK dependent repair has been demonstrated in numerous systems to increase sensitivity to both cancer treatment modalities (1014). Most DNA-PK inhibitors target the active site of the catalytic subunit DNA-PKcs and initial molecules lacked specificity, were metabolically unstable and possessed poor pharmacokinetic profiles that hampered initial development of these molecules $(15,16)$. More recently many of these liabilities have been addressed and clinical studies have advanced with Merck's (M3418/nedisertib) and Celgene's (CC-115) DNA-PK inhibitors being investigated as monotherapy and in combination with IR in the treatment of advanced solid tumors.

Herein we describe the discovery of highly potent and selective DNA-PK inhibitors whose mechanism of action is via blocking the $\mathrm{Ku} 70 / 80$ heterodimer interaction with DNA. We demonstrate a direct interaction of our compounds with the $\mathrm{Ku}$ heterodimer and inhibition of $\mathrm{Ku}-$ DNA binding and DNA-PKcs catalytic activity. We show potent inhibition of NHEJ catalyzed ligation activity in vitro in NHEJ-competent whole cell extracts, as well as decreased cellular NHEJ. Data are presented demonstrating the cellular response is a result of Ku inhibition and that the compounds potentiate cellular sensitivity to DSB-inducing agents. In addition, chemically targeted $\mathrm{Ku}$ inhibition improves the frequency of homology-directed repair (HDR) in CRISPR-Cas9 gene editing technology, thus providing new insights and utility of Ku-DBI's.

\section{MATERIALS AND METHODS}

\section{Chemistry}

The synthetic schemes, procedures and characterization of the compounds are provided in the Supplementary Data.

\section{Computational methods}

Docking studies were conducted using existing crystal structures of the Ku70/80 heterodimer (PDB: 1JEQ) and the $\mathrm{Ku} 70 / 80$ dimer bound to a 55-nucleotide DNA substrate (PDB:1JEY) obtained from the Protein Data Bank (PDB) and prepared using the Protein Preparation Wizard (17). Force field atom types and bond orders were assigned, missing atoms were added, tautomer/ionization states were assigned, water orientations were sampled, Asn, Gln and His residues were flipped to optimize the hydrogen bond network, and a constrained energy minimization was performed. Ku-DBi's were drawn in ChemDraw as MDL molfiles and prepared for docking using LigPrep including a minimization with the OPLS3 force field. All chiral centers were retained as specified in the literature. One low energy ring conformation per compound was generated. Ionization states and tautomer forms were enumerated at $\mathrm{pH} 7.0 \pm 2.0$ with Epik.

Ku-DBi's were flexibly docked into the cleft defined by residues using the Glide Extra-Precision (XP) protocol with default settings (18). Docking poses were evaluated based on visual interrogation and calculated docking score. The poses were selected according to the binding mode and the XP GScore. The Glide Extra-Precision (XP) scoring function was used for the potential amino acid interactions that were determined based on proximity to each compound as revealed by docking analysis. The $\mathrm{Ku} 70 / 80$ interactions with Ku-DBi's were viewed using Pymol with cartoon, surface, and compounds interaction views. All the molecular modelling within this study was performed using Maestro software, version 11 (Schrödinger) operating in a Linux environment.

\section{Protein purification}

The $\mathrm{Ku} 70 / 80$ heterodimer was purified from baculovirusinfected SF9 cells as previously described (19). DNA-PKcs was purified from HeLa cells or HEK 293 cells as described previously (20).

\section{Biochemical activity assays}

Electrophoretic mobility shift assays (EMSAs) were used to assess $\mathrm{Ku}-\mathrm{DNA}$ binding activity and the effect of potential inhibitors. Reactions were performed with a $\left[{ }^{32} \mathrm{P}\right]$-labeled 30-bp duplex DNA and purified $\mathrm{Ku}$. The DNA substrate was prepared by annealing $5^{\prime}-\left[{ }^{32} \mathrm{P}\right]-$ CCCTATCCTTTCCGCGTCCTTACTTCCCC-3' to its complement. $\mathrm{Ku}$ was pre-incubated with varying concentrations of compound before addition to the EMSA reaction mixture containing DNA. Reactions were incubated for $30 \mathrm{~min}$ at $25^{\circ} \mathrm{C}$ and products separated by electrophoresis on a $6 \%$ non-denaturing polyacrylamide gel. Gels were imaged using a PhosphorImager and quantified by ImageQuant (Molecular Dynamics) as we have described previously $(20,21)$.

Kinase assays to assess DNA-PK catalytic activity were performed measuring the DNA-dependent transfer of $\left[{ }^{32} \mathrm{P}\right]$ from ATP to a synthetic p53-based peptide substrate as described previously $(20,22)$. Briefly, compounds were preincubated with DNA-PKcs/Ku for 15 min and reactions initiated by the addition of ATP, DNA and peptide. The same 30 bp duplex DNA was used in kinase assays except without the $\left[{ }^{32} \mathrm{P}\right]$ label. The DNA-PK phosphorylation assays were performed at $37^{\circ} \mathrm{C}$ for $15 \mathrm{~min}$ and stopped with $30 \%$ acetic acid. Reaction products were spotted on P81- filter paper that was then washed five times for 5 min each in $15 \%$ acetic acid, then once in $100 \%$ methanol and allowed to dry. Filters were exposed to PhosphorImager screen and analyzed using ImageQuant software (Molecular Dynamics). Inhibitor titration assays (both EMSA and DNA-PK) were performed in triplicate and data fit to standard binding curves using GraphPad Prism to calculate $\mathrm{IC}_{50}$ values.

Autophosphorylation reactions were performed essentially as we have described (23). Briefly, DNA-PK was incubated as described above except omitting the peptide and radioactive tracer. Reactions were terminated by the addi- 
tion SDS sample buffer and heated to $70^{\circ} \mathrm{C}$ for $5 \mathrm{~min}$. Samples were separated by SDS PAGE on 4-20\% acrylamide denaturing gels and transferred to PVDF. Blots were blocked and probed with the DNA-PKcs phospho-Ser 2056 cluster specific Rabbit monoclonal antibody and secondary HRP conjugated goat-anti rabbit antibody. Images were captured using chemiluminescence detection. Blots were stripped, reprobed for total DNA-PKcs using a mouse monoclonal and goat anti mouse-HRP secondary and imaged via chemiluminescence.

\section{Thermal-shift assay (TSA)}

To directly address the interaction of $\mathrm{Ku}$-DBi's with the $\mathrm{Ku}$ protein we employed a TSA (24). A $220 \mu 1$ master reaction mixture of $\mathrm{Ku}$ with either DMSO as a vehicle control or the indicated $\mathrm{Ku}-\mathrm{DBi}$ was prepared and $20 \mu \mathrm{l}$ distributed into 10 individual tubes. The tubes were incubated at the indicated temperatures for $3 \mathrm{~min}$ in a thermocycler, cooled to $4^{\circ} \mathrm{C}$ and sedimented at $12,000 \times g$ for $20 \mathrm{~min}$. The soluble protein in the supernatant was collected and separated by SDS-PAGE, transferred to PVDF and $\mathrm{Ku} 70$ detected by western blot analysis using chemiluminescent detection. Quantification of band intensities was performed by MultiGage using a Fuji LAS-3000 imager.

\section{Kinase screen}

A screen of protein kinases was performed using the ADPGlow assay system (25). The 24-kinases selected for analysis and their substrate were obtained from Promega. Each kinase and its appropriate substrate were assayed in triplicate with and without $2.5 \mu \mathrm{M} \mathbf{6 8}$ or $\mathbf{2 4 5}$ in a 96-well plate format. The ADP generated was determined in a coupled luciferase assay following depletion of ATP and serves as a readout for phosphorylation. The degree of inhibition was calculated compared to the DMSO vehicle controls.

\section{In vitro $\mathrm{NHEJ}$ assay}

In vitro NHEJ assays were performed essentially as described previously (19). Briefly, reactions $(10 \mu 1)$ were performed in $50 \mathrm{mM}$ HEPES pH 8.0, $100 \mathrm{mM}$ KOAc, 0.5 $\mathrm{mM} \mathrm{Mg}(\mathrm{OAc})_{2}, 1 \mathrm{mM}$ ATP, $1 \mathrm{mM}$ DTT and $0.1 \mathrm{mg} / \mathrm{ml}$ bovine serum albumin (BSA) and the indicated concentration of $\mathrm{Ku}-\mathrm{DBi}$. pBluescript DNA was linearized with HindIII and $5^{\prime}-{ }^{32}$ P-labeled. Reactions contained $10 \mathrm{ng}$ of DNA and $25 \mu \mathrm{g}$ of whole cell extract. Reactions were incubated at $37^{\circ} \mathrm{C}$ for $2 \mathrm{~h}$, terminated by the addition of proteinase K/SDS/EDTA and incubated for an additional 30 $\min$ at $37^{\circ} \mathrm{C}$. Products were separated by electrophoresis on $0.6 \%$ agarose gels. Products were detected in dried gels by PhosphorImager (BioRad PMI) analysis.

\section{Cell culture}

Ku80-wt and null mouse embryo fibroblasts (MEF) were originally obtained from Dr Gloria Li (26) and NCI-H460 (ATCCR) HTB177 ${ }^{T M}$ ) (H460) cells were cultured in RPMI medium supplemented with $10 \%$ fetal bovine serum. Cells $\left(5 \times 10^{3}\right)$ were plated in wells of a 96-well plate and incubated for $24 \mathrm{~h}$ prior to any treatments. Cells were then treated with the $\mathrm{Ku}-\mathrm{DBi}$, bleomycin or etoposide as indicated for $48 \mathrm{~h}$ in Opti-MEM. The vehicle (DMSO) concentration was held constant at 1\%. Cell metabolism/viability was assessed by a mitochondrial metabolism assay (CCK8) assay as we have described previously (27). This assay is based on the generation of a water soluble formazan product by cellular dehydrogenases and is proportional to the number of living cells. Following 2-h incubation with CCK-8 reagent, absorbance was measured at $450 \mathrm{~nm}$ and compared to vehicle-treated controls to determine percent viability. The results presented are the average and SEM of triplicate determinations.

\section{NHEJ host-cell reactivation assay}

Analysis of cellular NHEJ-dependent repair of DSB lesions was performed using a host-cell reactivation assay as we have previously described (28). Briefly, H460 cells were seeded in 6-well plates and incubated $24-48 \mathrm{~h}$ prior to analysis. Cells were pre-treated for $2 \mathrm{~h}$ with vehicle or the indicated Ku-DBi in Opti-MEM (Gibco) with DMSO concentration held constant (1\%). Cells were then transfected by electroporation using Amaxa nucleofector device (Lonza) with AfeI-linearized pMax-GFP or undigested (circular) pMax-GFP (0.2 $\mu \mathrm{g}$, Lonza). Complete digestion of the pMax-GFP plasmid was confirmed by agarose gel electrophoresis prior to transfection; the blunt cut site is located between the pMax promoter and GFP expression sites, requiring NHEJ repair for GFP expression. Co-transfection with covalently closed circular pCMV-E2-Crimson $(0.2 \mu \mathrm{g}$, Takara Bio USA) was used as a transfection control in all experiments. Cells were incubated for $24-48 \mathrm{~h}$ as indicated to allow re-joining of the pMax-GFP. Expression of the fluorescence reporters was identified by flow cytometry (BD FACSCaliber). The NHEJ efficiency is presented as the ratio of GFP/E2-Crimson compared to control cells transfected with both reporters on covalently closed circular plasmids.

\section{Immunofluorescence microscopy}

H460 cells were cultured in 24-well plates on glass coverslips overnight prior to treatment. Cells were treated with $10 \mu \mathrm{M}$ Bleomycin for $1 \mathrm{~h}$ at $37^{\circ} \mathrm{C}$ and $20 \mu \mathrm{M} 245$ Inhibitor, concurrent or with 1 or $2 \mathrm{~h}$ pre-incubated $\mathrm{Ku}$ inhibitor. After 1-h Bleomycin treatment, cells were washed in PBS, fixed with $4 \%$ cold paraformaldehyde for $20 \mathrm{~min}$, permeabilized in $0.1 \%$ Triton X-100 for $10 \mathrm{~min}$, washed and blocked in blocking solution (3\% BSA, 5\% Goat serum in PBS) for 30 min at room temperature. Primary antibodies, rabbit anti phospho-DNA-PKcs S2056 (Abcam, ab124918) and mouse anti phospho- $\gamma$ H2A.X S139 (BioLegend, 613401) were prepared at 1:200 dilution in blocking solution and incubated overnight at $4{ }^{\circ} \mathrm{C}$. Then, an appropriate Alexa Fluor 488 or 594 conjugated secondary antibody was incubated in blocking solution for $2 \mathrm{~h}$ at room temperature. Cells on glass coverslips were mounted on slides in antifade mounting medium with DAPI (H-1500, VectaShield HardSet, Vector Laboratories). Images were captured digitally using the inverted multi-channel fluorescence EVOS FL Auto 2 Imaging System (Invitrogen) using 10X or 60X-immersion magnification. Images were subjected to fluorescence intensity 
A

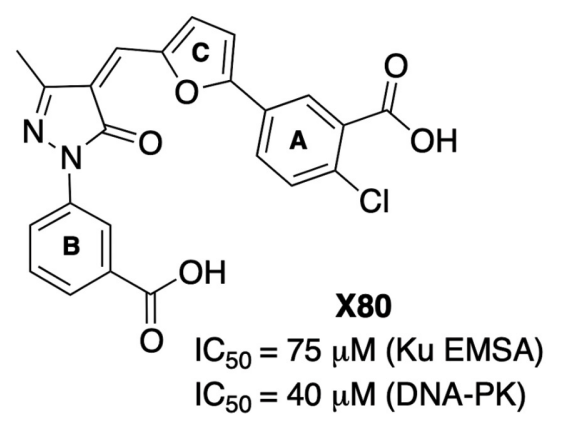

B

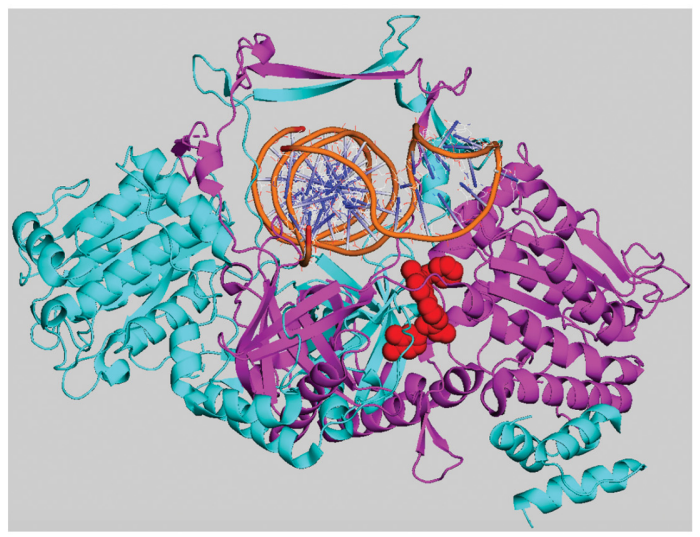

C

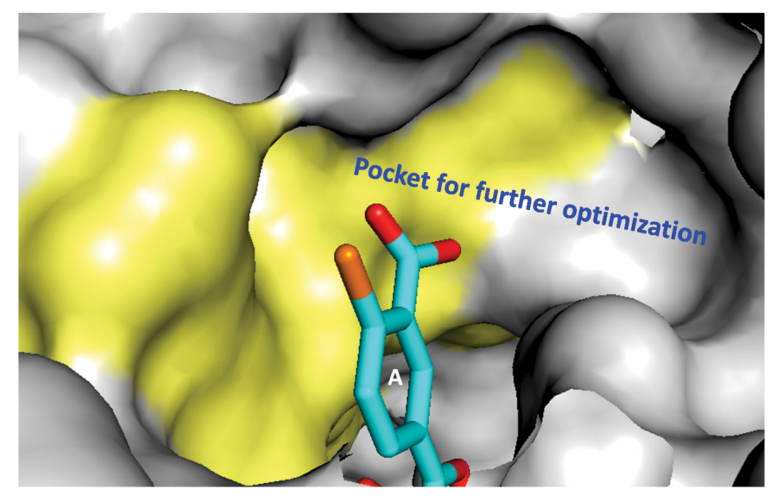

Figure 1. (A) Structure of X80 with Ku EMSA and DNA-PK IC 50 values.(B) Binding pocket of $\mathbf{X 8 0}$ in the Ku70/80 core. Ku70 is depicted in cyan and Ku80 in magenta. The DNA ring structure is depicted in orange (circular stick model) and X80 compound in red (spheres). (C) Schematic representation of SAR exploration rationale: a pocket surrounding Ring A of $\mathbf{X 8 0}$ compound for further optimization (Ku70 shown as yellow and Ku80 as gray surface).

quantification analysis using the extended ImageJ version FIJI. DAPI positive regions in 200 nuclei were defined as regions of interest (ROI) per field, and three fields were scored per condition. DAPI, DNA-PKcs p-S2056 and phospho$\gamma \mathrm{H} 2 \mathrm{~A} . \mathrm{X}$ S139 signals were determined in blue, green or red channels, respectively.

\section{Cell Irradiation}

H460 cells were seeded into 24-well plates $18-24 \mathrm{~h}$ prior to experiments. Two hours prior to irradiation, medium was replaced and fresh Opti-MEM medium containing either $\mathrm{Ku}-\mathrm{DBi}$ or DMSO vehicle was added to cells. Plates were placed on ice for 15 min prior to irradiation. Exponentially growing cells were then irradiated on ice with 2 or 5 Gy of $160 \mathrm{kVp}$ X-rays using a Precision X-ray machine (North Branford, CT) at a dose rate of $67.6 \mathrm{cGy} / \mathrm{min}$. Radiation dosimetry measurements were performed using a Farmer-type ionization chamber (PTW Model N30013, Freiburg, Germany) in conjunction with a Keithley electrometer (Model K602, Cleveland, Ohio). After irradiation, cells were incubated on ice $10 \mathrm{~min}$ before being allowed to recover at $37^{\circ} \mathrm{C}, 5 \% \mathrm{CO}_{2}$ for $24 \mathrm{~h}$. Viability was assessed by clonogenic survival assays. Cells were detached with trypsin, plated and incubated for 10-14 days. Plates were then fixed, stained and colonies counted. Surviving fractions were determined and normalized to the plating efficiency of cells treated with vehicle only.

\section{RESULTS}

\section{Optimization of small molecule chemical Ku inhibitors}

During our efforts to expand DNA repair targeted therapy, we found the compound X80 (Figure 1A) displayed modest in vitro inhibitory activity when assessing $\mathrm{Ku}$ doublestranded DNA-binding activity in vitro. We screened a series of ester and carboxylic acid derivatives of the arylpyrazolone moiety (Ring B) and aryl/alkyl ester and amide derivative of Ring A, to identify compounds 5102 and 5135, which displayed dramatically increased potency but both compounds were very insoluble and unstable making them of limited utility for in vitro or cellular analysis (29). Having determined that modifications of X80 could yield more active compounds, we embarked on a multidisciplinary structure-guided synthetic chemistry effort to create high affinity compounds with favorable chemical properties. Utilizing the existing crystal structures of the $\mathrm{Ku} 70 / 80$ heterodimer (PDB: 1JEQ) and the $\mathrm{Ku} 70 / 80$ dimer bound to a 55-nucleotide DNA substrate (PDB: 1JEY) we identified a ligand binding pocket for the $\mathbf{X 8 0}$ core structure located in close proximity to the central DNA-interaction region that surrounds the DNA helix (Figure 1B). The prospective binding pocket spans the interface between the $\mathrm{Ku} 70$ (cyan) and Ku80 (magenta) subunits. Closer examination revealed a space-filling pocket located adjacent to ring $\mathrm{A}$ of $\mathbf{X 8 0}$ which spans the interface between the two $\mathrm{Ku}$ subunits (Figure 1C). This interface could accommodate the 


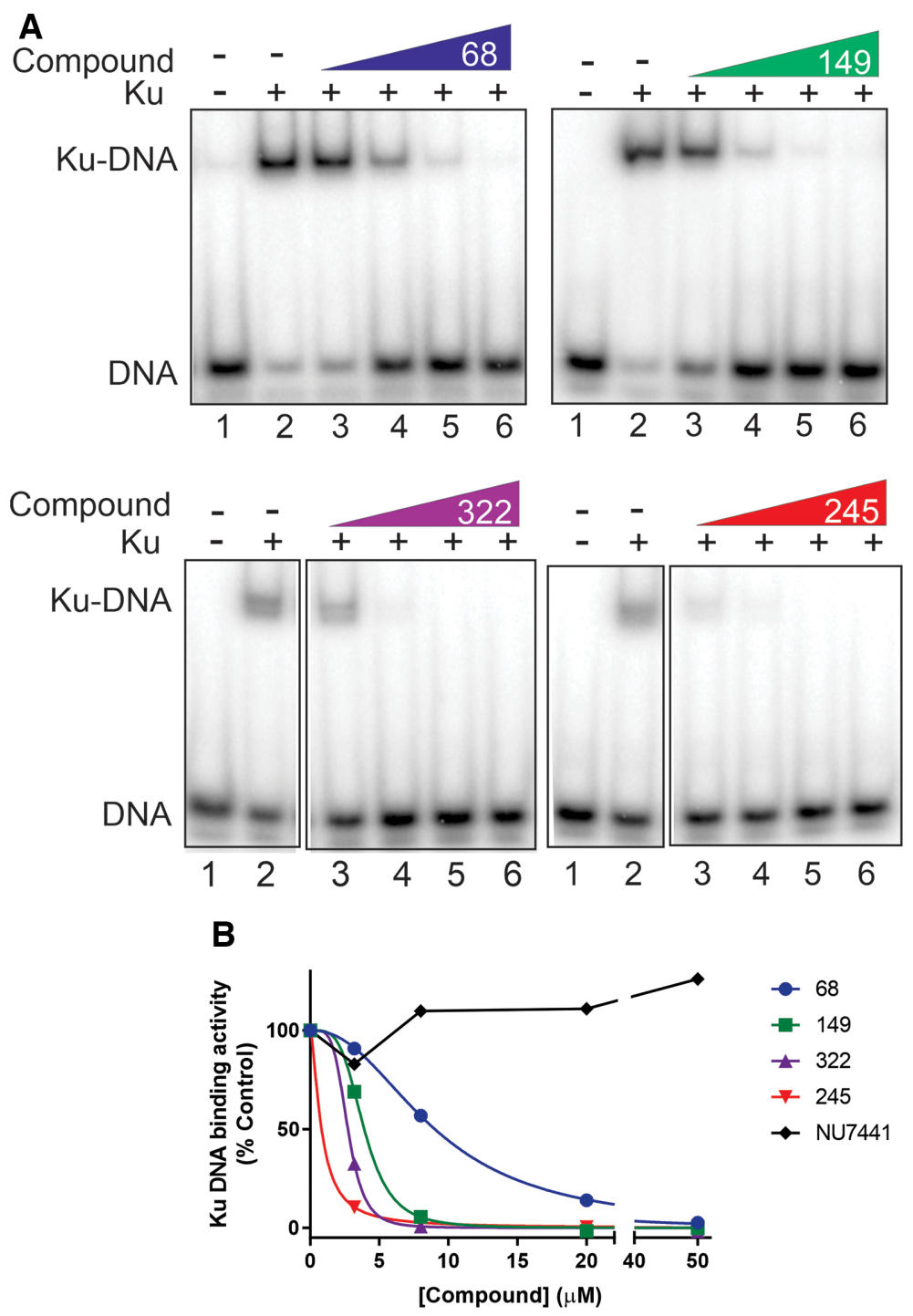

Figure 2. EMSA analysis of Ku inhibitors. (A) Inhibition of Ku-DNA binding as assessed by EMSA. Binding assays were performed as described in 'Materials and Methods' section. The indicated compounds were incubated in reaction with DNA and purified Ku, reaction products were separated by native gel electrophoresis. Gels were visualized and quantified by PhosphorImager analysis. (B) Quantification of EMSA data. $\mathrm{IC}_{50}$ values were calculated from a minimum of three independent experiments using GraphPad Prism and data are presented in Table 1.

additional phenyl rings present in the potent $\mathbf{5 1 0 2}$ and $\mathbf{5 1 3 5}$ molecules (29). We therefore altered the linkage from an ester to an amide to probe this pocket with various $\mathbf{X 8 0}$ derivatives. The most effective modification we identified was the incorporation of a 3-methoxyphenyl moiety to generate compound 68. This modification resulted in a 4-fold increase in $\mathrm{Ku}-\mathrm{DNA}$ binding inhibitory activity (Figure 2) and a significant increase in solubility compared to the $\mathbf{5 1 0 2}$ and $\mathbf{5 1 3 5}$ derivatives.

The core of the $\mathbf{X 8 0}$ compound contains carbon-carbon double bond (alkene) between the furan and pyrazolone rings and as such, $\mathbf{X 8 0}$ derivatives exist as a racemic mixture of $Z$ and $E$ isomers with the $\mathrm{Z}$ isomer the major product $(\sim 73-80 \%)$ as determined by NOESY NMR analysis (data not shown). To explore the importance of the double bond we reduced the double bond to a single bond, gen- erating compound 149 thatresulted in a further increase in $\mathrm{Ku}$ inhibitory activity (Figure 2) compared to $\mathbf{6 8}$. The replacement of methyl group of pyrazolone ring in compound 149 with a bioisosteric trifluoromethyl group resulted in compound 322, and again, a further increase in potency against $\mathrm{Ku}$ in a DNA-binding assay was observed. These data demonstrate that the double bond is in fact not critical for Ku inhibitory activity and instead is somewhat detrimental to the $\mathrm{Ku}$-inhibitor interaction.

For the final step of optimization, we assessed how bioisosteric modification of the carboxylic acid of phenyl Ring B of compound 149 impacts inhibitory activity. In silico docking studies showed that carboxylic acid moiety (Ring B) form a hydrogen bond with Arg368 (Figure 3A) that we posited is important for $\mathrm{Ku}$ inhibition. Interestingly, replacement with a carboxylic acid bioisostere, tetra- 

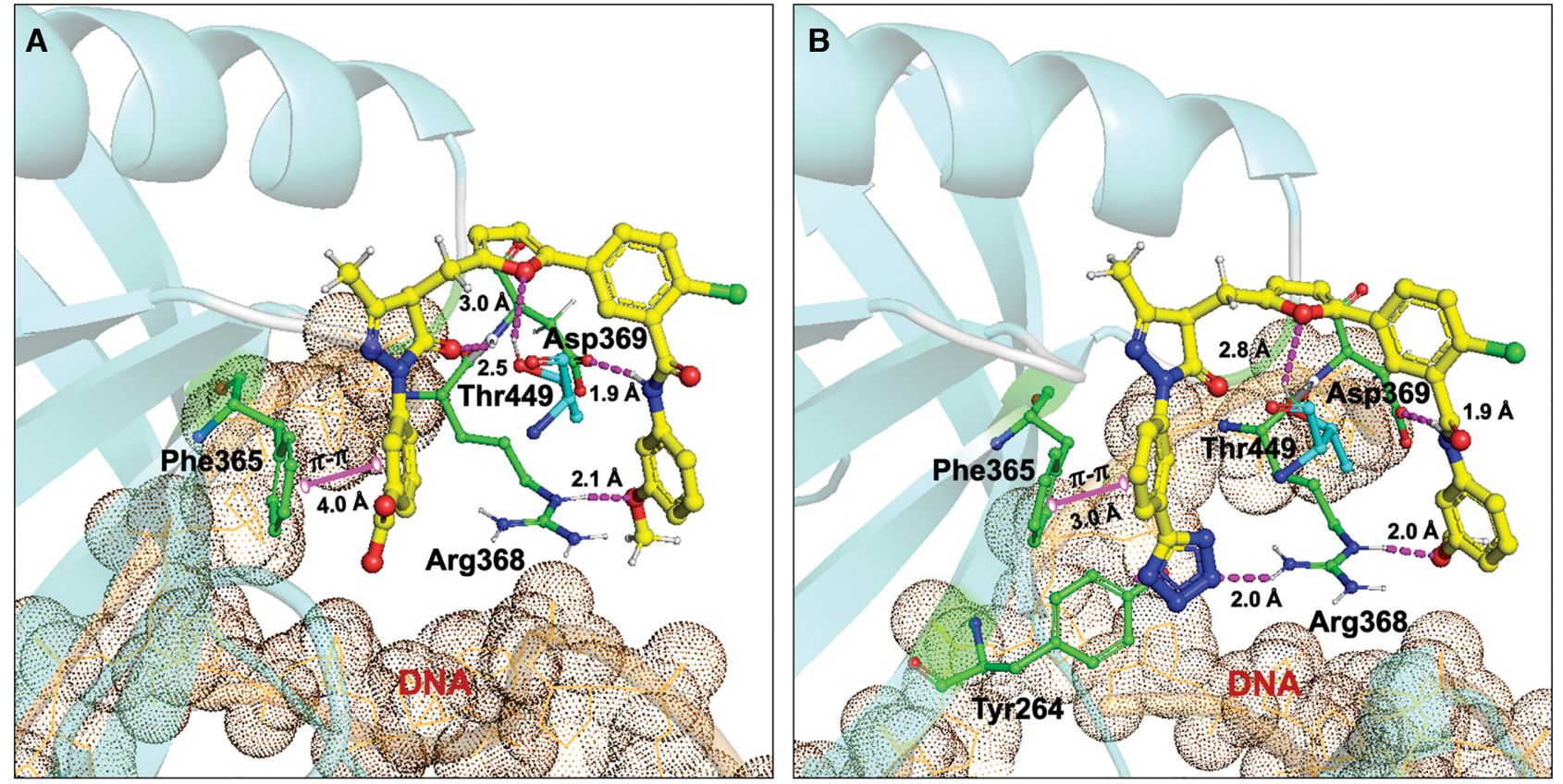

Figure 3. Molecular docking studies (PDB: 1JEQ and 1JEY). (A and B) Molecular interactions of compound 149 (A) and 245 (B) (all in yellow carbon) with $\mathrm{Ku} 70 / 80$ heterodimer (key amino acids are shown in cyan carbon (Ku70), green carbon (Ku80) and cartoon is shown in cyan color). The DNA ring structure is depicted in light orange dots. Interaction with amino acid side chains is indicated with the dashed magenta lines and $\pi-\pi$ stacking interactions are shown in solid magenta dumbell. Interaction distances indicated in $\AA$.

zole (compound $\mathbf{2 4 5}$ ) showed potent $\mathrm{Ku}$ inhibitory activity and molecular docking showed more tight binding than carboxylic acid moiety for tetrazole moiety with $\mathrm{Ku}$ protein (Figure 3B). The tetrazole moiety and 3-methoxyphenyl group of compound $\mathbf{2 4 5}$ form a hydrogen bond network with a key residue, Arg368. In addition, phenyl-tetrazole moiety is well positioned to make $\pi-\pi$ stacking interactions with Phe365. The core structure of compound $\mathbf{1 4 9}$ and $\mathbf{2 4 5}$ was mainly stabilized in a large hydrophobic cavity, hydrogen bond networks, cation $-\pi$ and $\pi-\pi$ interactions with amino acid residues spans in the interface between the $\mathrm{Ku} 70$ and $\mathrm{Ku} 80$ subunits. The amino acid residues involved in the binding pocket are Tyr264, Phe365, Ala366, Ala367, Arg368, Asp369, Asp370, Glu371, Ala374, Leu377, Ser 378 in Ku80 and Tyr416, Glu417, Met446, Pro447, Phe448, Thr449, Glu450, Lys451 and Ile452 in Ku70. Molecular docking (GLIDE) determined similar binding positions for both compounds, with lowest predicted GLIDE XP scores of -7.06 and $-7.51 \mathrm{kcal} / \mathrm{mol}$ for 149 and 245, respectively. Both compounds exhibited a good correlation between docking scores and biological activities (Table 1) (18). The 2D interactions of compound 149 and 245 are provided in the Supplementary Data (Supplementary Figure S1). These data support the importance of the hydrophobic cavity and hydrogen bond network of the carboxylic acid (compound 149) and the tetrazole bioisostere (compound 245), showed potent Ku inhibitory activity and molecular docking revealed similar tight interactions with the $\mathrm{Ku}$ protein (Figure $3 \mathrm{~A}$ and $\mathrm{B}$ ). These data support the importance of the hydrogen bond network in facilitating and/or stabilizing the compound-Ku interaction.

\section{Mechanism of DNA-PK inhibition}

Having established a library of compounds with good stability, solubility and potent Ku inhibition we assessed their effects on DNA-PK kinase activity. In vitro kinase assays were performed and the results revealed that the X80 derivatives were potent inhibitors of DNA-PK kinase activity (Figure 4). Interestingly, the $\mathrm{IC}_{50}$ values calculated from titration experiments revealed lower values compared to those derived from $\mathrm{Ku}$ inhibitory experiments (Table 1). These results are likely a function of the different assays, with $\mathrm{Ku}$ binding being a stopped, stoichiometric assay and the kinase assay being a steady-state kinetic assay. The kinase activity data compared favorably to data obtained with the commercially available catalytic site targeted agent, Nu7441, which displayed nanomolar $\mathrm{IC}_{50}$ values in the kinase assay in vitro while having no impact on the $\mathrm{Ku}-\mathrm{DNA}$ binding activity (Figures 2B and 4B). These results confirm the novel mechanism of action of the $\mathrm{Ku}$ inhibitors to inhibit DNA-PK by blocking the $\mathrm{Ku}-\mathrm{DNA}$ interaction.

The in vivo relevant phosphorylation of DNA-PK is the autophosphorylation of the Ser 2056 cluster (30). We therefore determined the impact of our Ku-DBi's on in vitro autophosphorylation of DNA-PKcs via western blot analyses. The data presented in Figure 4C demonstrate that in fact the autophosphorylation of the Ser 2056 cluster is inhibited by the individual Ku-DBi's. The inhibition is specific as a control DNA-protein interaction inhibitor $\mathbf{3 2 9}$ which targets replication protein A (31) does not impact Ser 2056 autophosphorylation.

While the development of X80 derivatives focused on optimizing direct interactions with the Ku proteins, the mechanism could be a function of the compounds binding to 
Table 1. Chemical structures and activity profile of Ku-DBi's<smiles>COc1cccc(NC(=O)c2cc(-c3ccc(/C=C4\C(=O)N(c5cccc(C(=O)O)c5)N=C4C)o3)ccc2Cl)c1</smiles><smiles>[R]C1=NN(c2cccc(C(=O)O)c2)C(=O)C1Cc1ccc(-c2ccc(Cl)c(C(=O)Nc3cccc(OC)c3)c2)o1</smiles><smiles>COc1cccc(NC(=O)c2cc(-c3ccc(CC4C(=O)N(c5cccc(-c6nnn[nH]6)c5)N=C4C)o3)ccc2Cl)c1</smiles>
245
Assays
68
149
322
$0.24 \pm 0.015 \mu \mathrm{M}$
DNA-PK $\left(\mathrm{IC}_{50}\right)^{\mathrm{a}}$
$3.12 \pm 0.7 \mu \mathrm{M}$
$0.50 \pm 0.03 \mu \mathrm{M}$
$0.11 \pm 0.02 \mu \mathrm{M}$
$1.99 \pm 0.9 \mu \mathrm{M}$
$\mathrm{Ku} 70 / 80\left(\mathrm{IC}_{50}\right)^{\mathrm{b}}$
$6.02 \pm 2.2 \mu \mathrm{M}$
$3.72 \pm 1.5 \mu \mathrm{M}$
$2.66 \pm 0.3 \mu \mathrm{M}$
$-7.51$
Glide Gscore ${ }^{c}$
ND
$-7.06$
ND

aDetermined using DNA-PK phosphoryl-transferase catalytic assay, using a synthetic p53 peptide substrate and highly purified DNA-PK kinase. A commercially available selective DNA-PK inhibitor, NU7441 showed IC $5030 \mathrm{nM}$ in this assay. ${ }^{\mathrm{b}}$ Compounds were incubated with purified Ku70/80 proteins and direct DNA binding activity measured using EMSA. 'Predicted molecular docking GLIDE XP Gscore were obtained as described in the MATERIAL and METHODS. ND, Not Determined.

DNA and inhibiting the binding of $\mathrm{Ku}$. We first assessed binding to DNA using a fluorescence displacement assay (FDA) as we have described for the previous X80 derivatives (21). Similar to previous results, the data obtained with the newer derivatives show minimal direct DNA interaction up to concentrations $10 \times$ the calculated $\mathrm{IC}_{50}$ 's for DNA-PK kinase activity (Supplementary Figure S2). Therefore, direct DNA binding or intercalation of the Ku-DBi's cannot account for the observed inhibition of $\mathrm{Ku}-\mathrm{DNA}$ binding activity and DNA-PK kinase activity. To determine if in fact the $\mathrm{X} 80$ derivatives were binding directly to Ku to impart inhibitory activity we employed a thermal stability shift assay (TSA). In this assay, the thermal stability of the $\mathrm{Ku}$ protein is assessed and the impact of X80 derivative binding on the denaturation profile determined. Briefly, the protein is incubated with vehicle or a fixed concentration of inhibitor and then heated to different temperatures. After heating, the solution is sedimented to precipitate denatured protein. The soluble protein is then separated by SDS-PAGE and detected by western blot analysis. The data demonstrate that $\mathrm{Ku}$ denatures with a $T_{\mathrm{m}}$ of $50^{\circ} \mathrm{C}$. The addition of compound 245 resulted in a $6^{\circ} \mathrm{C}$ shift in $T_{\mathrm{m}}$ to $56^{\circ} \mathrm{C}$ (Figure $5 \mathrm{~A}$ and B). Altogether, the FDA and TSA support the conclusion that the X80 derivatives inhibit the $\mathrm{Ku}-\mathrm{DNA}$ interaction by directly binding to the $\mathrm{Ku}$ protein and competitively blocking its association with DNA. The inability to form a functional $\mathrm{Ku}-\mathrm{DNA}$ complex on the DNA termini leads to reduced DNA-PK catalytic activity by inhibiting the DNA$\mathrm{PKcs}-\mathrm{Ku}-\mathrm{DNA}$ complex necessary for kinase activity. This represents a novel mechanism of DNA-PK inhibition where kinase activity is abrogated by blocking the $\mathrm{Ku}-\mathrm{DNA}$ interaction.

\section{Specificity of Ku-DBi's}

Having established the activity of these compounds in vitro, we sought to assess their specificity. As we originally discovered the X80 class of compounds in a virtual screen based on XPA (Xeroderma Pigmentosum Group A), we determined the cross reactivity of the $\mathrm{Ku}$-targeted $\mathrm{X} 80$ derivatives with XPA. No inhibition of XPA-DNA binding activity was observed at concentrations below $20 \mu \mathrm{M}$ (data not shown). These data also support the novel mechanism of action of Ku-DBi's as a direct DNA-binding molecule would be expected to block other DNA-binding proteins. With the explosion of kinase inhibitor development and assays to determine kinase specificity, we assessed a series of kinases for inhibition with Ku-DBi's. As DNA-PK is the only kinase that requires $\mathrm{Ku}$ DNA binding for activity we would expect minimal inhibitory activity against other kinases. The results demonstrate that the majority of the 24 kinases tested are not appreciably inhibited by the X80 derivatives (Figure 5C) at $2.5 \mu \mathrm{M}$ concentration which is close to the $\mathrm{IC}_{50}$ of compound $\mathbf{6 8}$ and $10 \times$ to the $\mathrm{IC}_{50}$ of compound $\mathbf{2 4 5}$ in DNA-PK kinase assay. Interestingly, the MELK kinase does show moderate inhibition by $\mathbf{2 4 5}$ consistent with previous data demonstrating that arylpyrazolone moiety possesses considerable affinity for the kinase active site and blocks kinase activity (32). Similarly, the PIM1 kinase possesses affinity for 3,5-diphenyl substituted indole/oxoindolins that adopt a similar conformation to the $\mathbf{X 8 0}$ derivatives and amide modification increased the affinity, consistent with the activity of inhibitors 68 and 245 $(33,34)$. Overall these data demonstrate the ability to design potent and specific inhibitors of the $\mathrm{Ku}-\mathrm{DNA}$ interaction. 
A

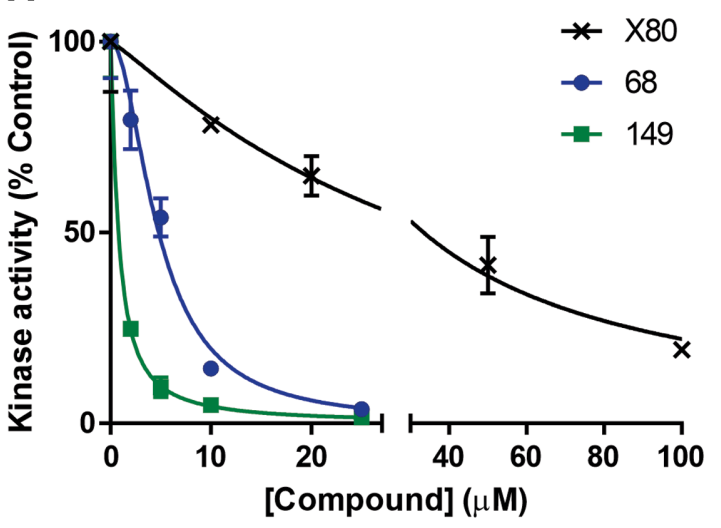

B

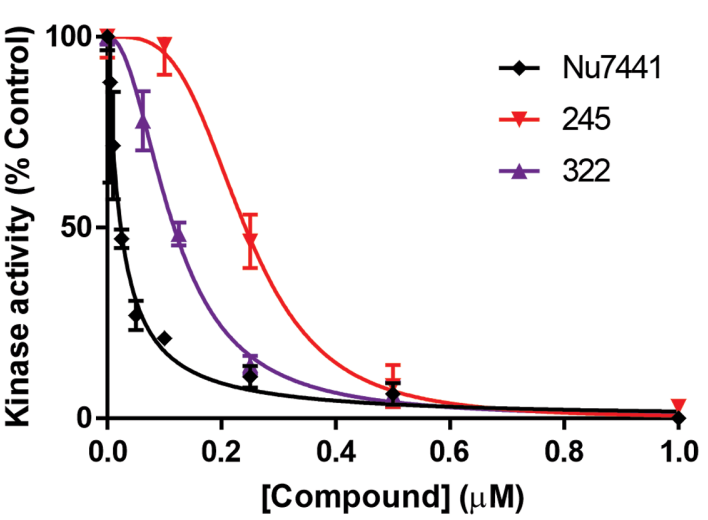

C

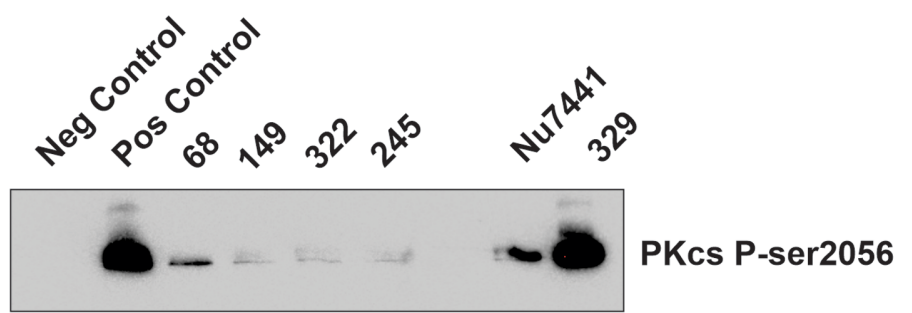

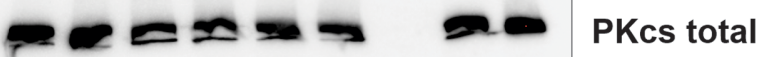

Figure 4. DNA-PK activity is inhibited by Ku targeted agents. (A and B). Kinases assays were performed as described in 'Materials and Methods' section with the indicated compounds. Data are the average and standard error of 2-3 replicates and $\mathrm{IC}_{50}$ values were calculated using GraphPad Prism and data presented in Table 1. (C) Autophosphorylation of DNA-PKcs at the Ser 2056 cluster was assessed in vitro and detected by western blot analysis as described in 'Materials and Methods' section. The negative control contained no DNA and ATP and positive control was with DMSO (vehicle). The individual KuDBi's $(20 \mu \mathrm{M})$, positive inhibitory control $(\mathrm{Nu} 7441,5 \mathrm{nM})$ and a negative control $(329,10 \mu \mathrm{M})$ were included as indicated. Reaction products were separated by SDS-PAGE, transferred to PVDF and probed sequentially to detect phospho-DNA-PKcs (upper panel) and total DNA-PKcs (lower panel) as indicated.

\section{Chemical Ku inhibition blocks NHEJ-catalyzed repair of DSBs}

To determine how chemical inhibition of Ku affects NHEJ, we performed an in vitro assay to assess the joining of DNA termini catalyzed in cell-free extracts (28). Briefly, linearized plasmid DNA (3 kbp) is incubated with a cell-free extract prepared from NHEJ-competent cells (HEK 293) and ATP. Data demonstrate that all Ku inhibitors tested (6 out of 6) inhibited in vitro NHEJ. The representative experiment shows inhibition of end-joining in a concentrationdependent manner for compound 149 (Figure 6A). These data demonstrate target engagement in a complex protein mixture and inhibition of DNA-PK dependent NHEJ. The relative potency compared to the our EMSA and kinase assay is somewhat reduced which suggests that in the complex cell-free extract the effective concentration of $\mathrm{Ku}-\mathrm{DBi}$ is reduced possibly via low affinity interactions with other proteins or is being degraded. Data supporting the reduced effective concentration in extracts was obtained in analysis of DNA-PKcs autophosphorylation where the potency of $\mathrm{Ku}-\mathrm{DBi}$ 's was reduce compared to highly purified DNA-PK preparations (data not shown).

Having demonstrated inhibition of NHEJ in vitro, we sought to determine if the chemical $\mathrm{Ku}$ inhibitors could abrogate cellular NHEJ. We employed a host cell reactivation assay in H460 cells as we have previously described to measure cellular NHEJ activity $(28,35)$. Briefly, a linearized plasmid encoding a GFP gene was transfected into cells along with a circular RFP expression plasmid as a transfection control. GFP expression is obtained only upon NHEJ-mediated re-circularization of the plasmid. The ratio of green to far-red cells is used for quantification as measured by flow cytometry. The data presented in Figure 6B demonstrate that all Ku-DBi's are capable of significantly reducing NHEJ-catalyzed repair events. The data show an approximate $50 \%$ reduction in NHEJ catalyzed repair events. Interestingly, the relative difference between the individual Ku-DBi's was not evident in this assay suggesting other factors beyond potency against $\mathrm{Ku}$ is impacting cellular activity and could include non-specific protein binding, cellular uptake or metabolism.

\section{Cellular sensitization to DSBs and assessment of on-target activity}

Having determined that our $\mathrm{Ku}$ inhibitors block cellular NHEJ, we performed the crucial experiment to determine if Ku-DBi's were working through DNA-PKes activity. We 
A

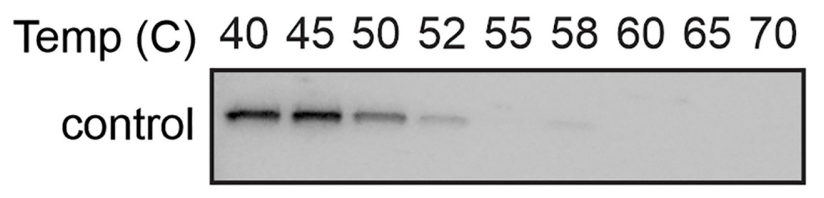

245

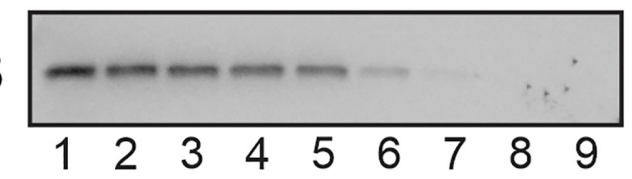

B

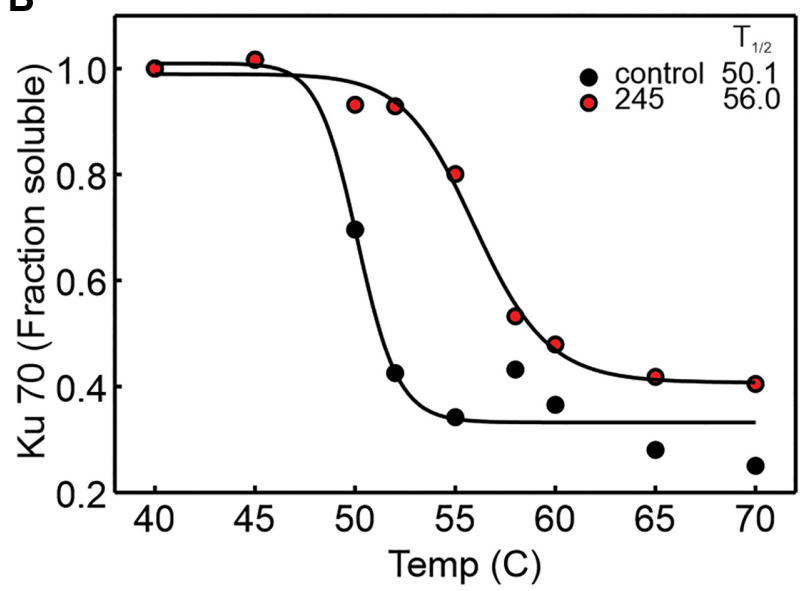

C

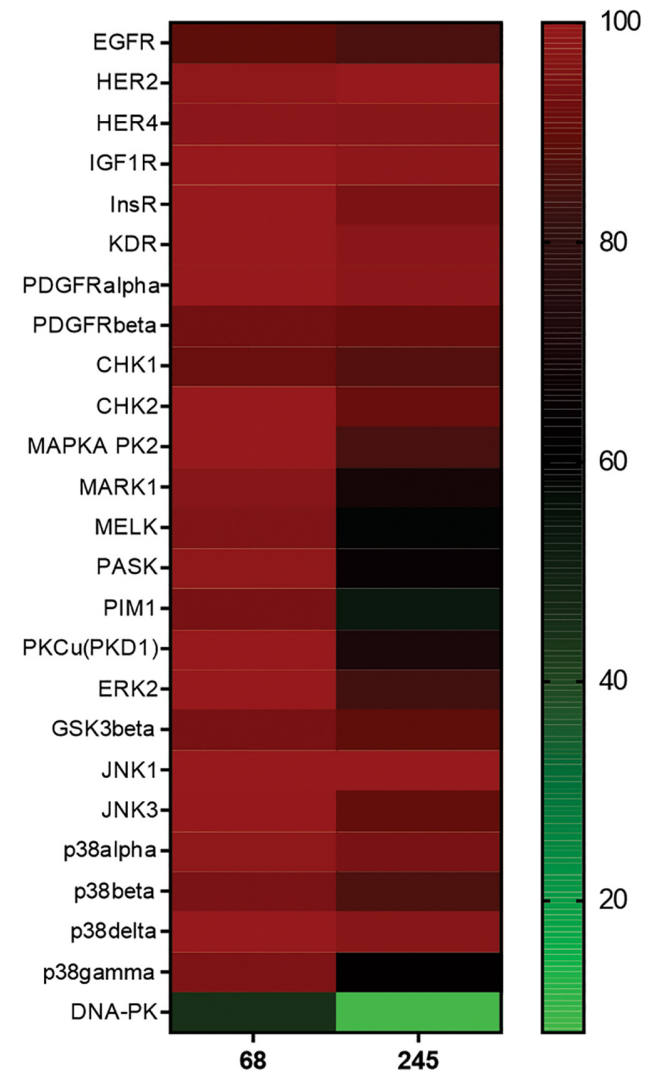

Figure 5. Thermal-shift assay (TSA) of Ku protein. (A) Purified Ku was treated with vehicle or $\mathbf{2 4 5}$ and thermal stability measured by Ku70 western blot. (B) Band intensity was normalized to the $40^{\circ} \mathrm{C}$ point and plotted versus temperature. Data were fit to a 4-parameter sigmoidal curve and $T_{1 / 2}$ determined. The error associated with the fits were $<0.5^{\circ} \mathrm{C}$. (C) Kinase specificity. The indicated compounds were assessed in a kinase screen using ADP-Glo as described in 'Materials and Methods' section. The percent activity remaining for each kinase was calculated and presented as a heat map.

therefore determined the impact of $\mathbf{2 4 5}$ treatment on phosphorylation of the DNA-PKcs Ser 2056 cluster. The experimental design is depicted in Figure 7A. We assessed 1 and $2 \mathrm{~h} 245$ pre-incubation prior to $1 \mathrm{~h}$ exposure to Bleomycin and concurrent $1 \mathrm{~h}$ combination treatment with 245 and Bleomycin. Following treatment, cells were processed for immunofluorescence detection of DNA-PKcs pS2056 and $\gamma$-H2AX. Representative images (Figure 7B) and quantification of the data (Figure 7C) demonstrate reduced Ser 2056 phosphorylation as a function of $\mathbf{2 4 5}$ treatment. The data also demonstrate that pre-incubation results in a greater decrease in autophosphorylation. Analysis of $\gamma$ H2AX also demonstrate an inhibition of the DDR as a function of 245, though the impact of pre-incubation was less apparent (Figure 7B and D). Analysis of autophosphorylation was confirmed by western blot analysis with a series of Ku-DBi’s (Supplementary Figure S3).

Having determined the ability to inhibit NHEJ in cells via abrogation of DNA-PKcs activity we sought to determine if Ku-DBi's could sensitize cells to DNA DSBinducing agents and determine if this effect is the result of a direct on-target interaction between the $\mathrm{Ku} \mathrm{70/80} \mathrm{het-}$ erodimer and the $\mathrm{Ku}-\mathrm{DBi}$. To determine if the chemical inhibition of $\mathrm{Ku}$ impacts sensitivity to DNA DSB inducing agents, we assessed cell viability of wild type (wt) and $\mathrm{Ku}$ 80-null MEFs to a DSB-inducing agent with and with- out Ku-DBi's. The data presented in Figure 7E shows cellular viability in cells treated with increasing concentrations of the radiomimetic drug Bleomycin with and without $\mathrm{Ku}-$ DBi's. Cells were treated concurrently for $48 \mathrm{~h}$ with $20 \mu \mathrm{M}$ 68 and the indicated concentrations of Bleomycin. We selected $20 \mu \mathrm{M} 68$ based on preliminary single agent experiments demonstrating less than a $10 \%$ reduction in survival, consistent with limited toxicity in normal cells. As expected, $\mathrm{Ku} 80$-null cells displayed increased sensitivity to Bleomycin ( $\sim 6$-fold) compared to the wt MEFs. The increased sensitivity to Bleomycin induced by $\mathbf{6 8}$ is also readily apparent in the wild type cells (compare black circles to blue circles). Importantly, there is no significant increase in sensitivity induced by $\mathbf{6 8}$ in the Ku80-null cells (compare black triangles to blue triangles). These data conclusively demonstrate that the observed sensitization effect of $\mathbf{6 8}$ to Bleomycin is mediated through on-target inhibition of $\mathrm{Ku}-\mathrm{DNA}$ binding by the Ku-DBi. The data also demonstrate that chemical inhibition with $\mathrm{Ku}-\mathrm{DBi} \mathbf{6 8 d o e s}$ not reach the sensitivity of the $\mathrm{Ku}$ null cells. This indicates there remains the possibility to increase the cellular activity of these inhibitors by either increasing potency or cellular uptake and stability.

A similar series of experiments were conducted to assess the impact of $\mathrm{Ku}$-DBi's on radiosensitivity. $\mathrm{H} 460$ cells were treated in 24-well plates with either vehicle or the indicated $\mathrm{Ku}-\mathrm{DBi}$ for $2 \mathrm{~h}$ prior to irradiation with either 2 or $5 \mathrm{~Gy}$ of 

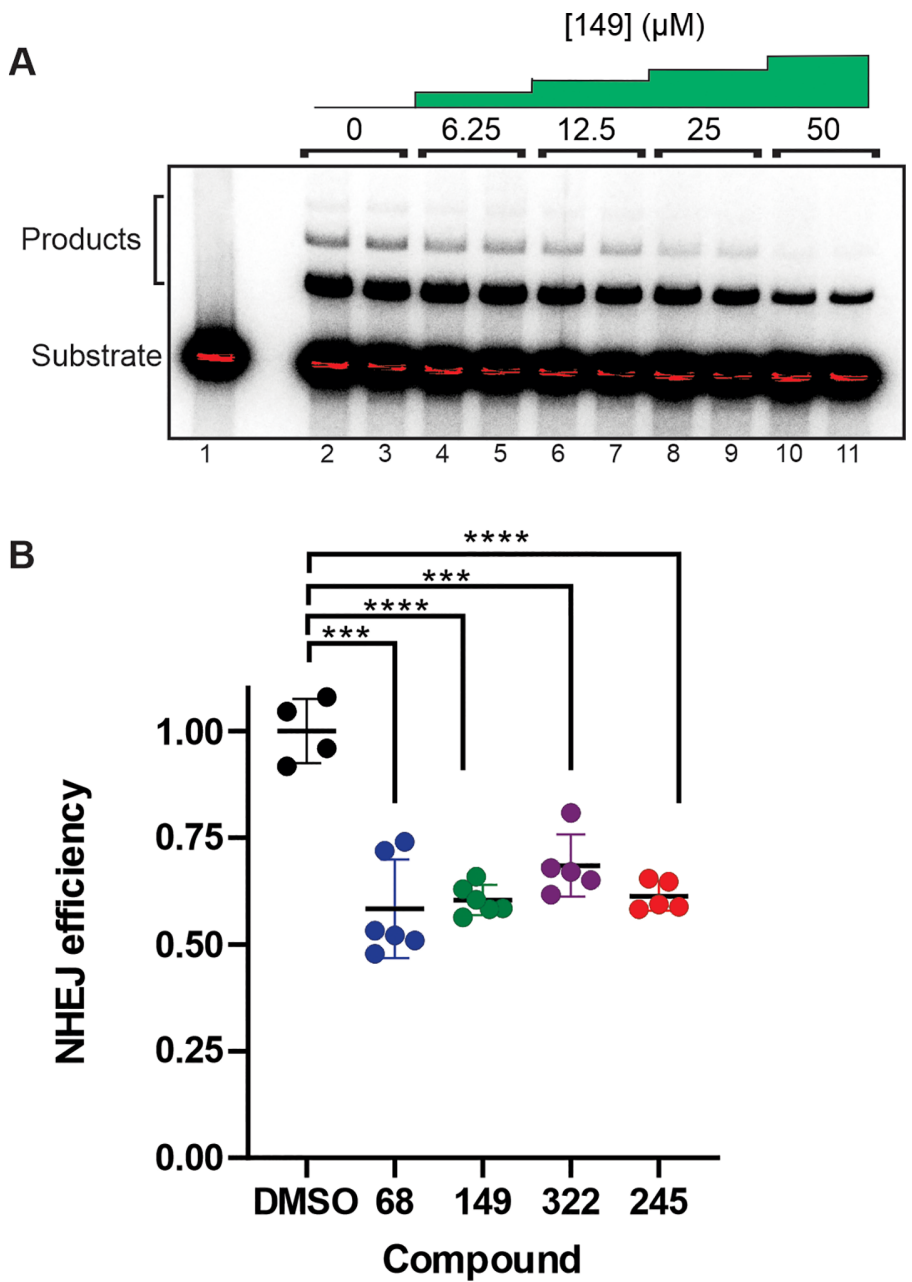

Figure 6. Analysis of Ku targeted DNA-PK inhibitors on in vitro and cellular NHEJ. (A) A radiolabeled linearized plasmid DNA (3 kbp) substrate (lane 1) and the formation of plasmid multimers when increasing concentration of compound 149 was incubated with the extract (lanes 2-11). Quantification of the data revealed an $\mathrm{IC}_{50}$ of $\sim 15 \mu \mathrm{M}$ for compound 149. (B) Cellular NHEJ was assessed by host cell reactivation as described in 'Materials and Methods' section. Individual data points are presented along with the average and standard error $(* * * * \mathrm{p}<-0.0001, * * * \mathrm{p}<0.001+$.

X-rays. Cells were allowed to recover for $24 \mathrm{~h}$ then plated for colony formation and determination of clonogenic survival. An enhancement of radiosensitivity was observed in cells treated with the Ku-DBi's and the relative sensitization follows the in vitro potency for the Ku-DBi's (Figure 7F). Similar results were observed when the effect of $\mathbf{3 2 2}$ on cellular sensitivity to etoposide was assessed (Figure 7G) though the degree of sensitization was reduced compared to Bleomycin and IR. This may be a function of how important Ku dependent NHEJ is for the different type of damage induced by the different agents. Together these data demonstrate that Ku-DBi's are capable of inhibiting DNA-PKcs, reducing NHEJ-catalyzed repair and ultimately can sensitize cells to a variety of DNA DSB inducing agents.

\section{Increased efficiency of HDR-mediated gene editing by chem- ical inhibition of $\mathrm{Ku}$}

Recent studies have shown that reduced NHEJ activity in vivo results in increases in HDR activity, and this phenomenon can be exploited to increase the efficiency of
HDR-mediated CRISPR/Cas9 precision genome engineering (36-39). To investigate the effect of $\mathrm{Ku}$ inhibitors on CRISPR/Cas9 genome editing, a donor molecule encoding a GFP and a puromycin resistance gene flanked by 800 bp of sequence homologous to a CRISPR cut site in the EMX1 gene was synthesized (Sigma). Donor, gRNA targeted to EMX1 and Cas9 plasmids were co-transfected into $\mathrm{H} 460$ cells in the presence and absence of $\mathrm{Ku}$ inhibitor $\mathbf{2 4 5}$. Seventy-two hours after transfection, cells were single-cell diluted in 96-well plates and placed under puromycin selection and cultured until confluent. Cells were harvested and genomic DNA isolated for PCR analysis. Junctional PCR analysis was used to assess homologous integration of the donor molecule (Figure 8). Of the 28 puromycin resistant clones from the vehicle treatment, 4 of them were positive for precise homologous integration of the transgene (Table 2). Conversely, 4 out of the 5 puromycin resistant clones derived from the cells treated with $20 \mu \mathrm{M} 245$ were positive for precise homologous integration of the transgene (Table 2). These results indicate that treatment with $\mathrm{Ku}$ inhibitor increased the efficiency of HDR-mediated gene in- 
A 245

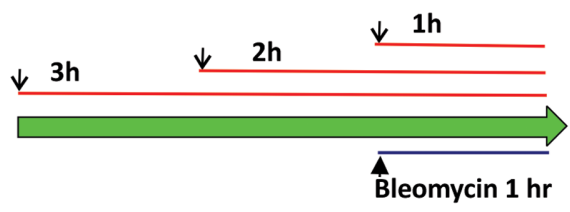

B

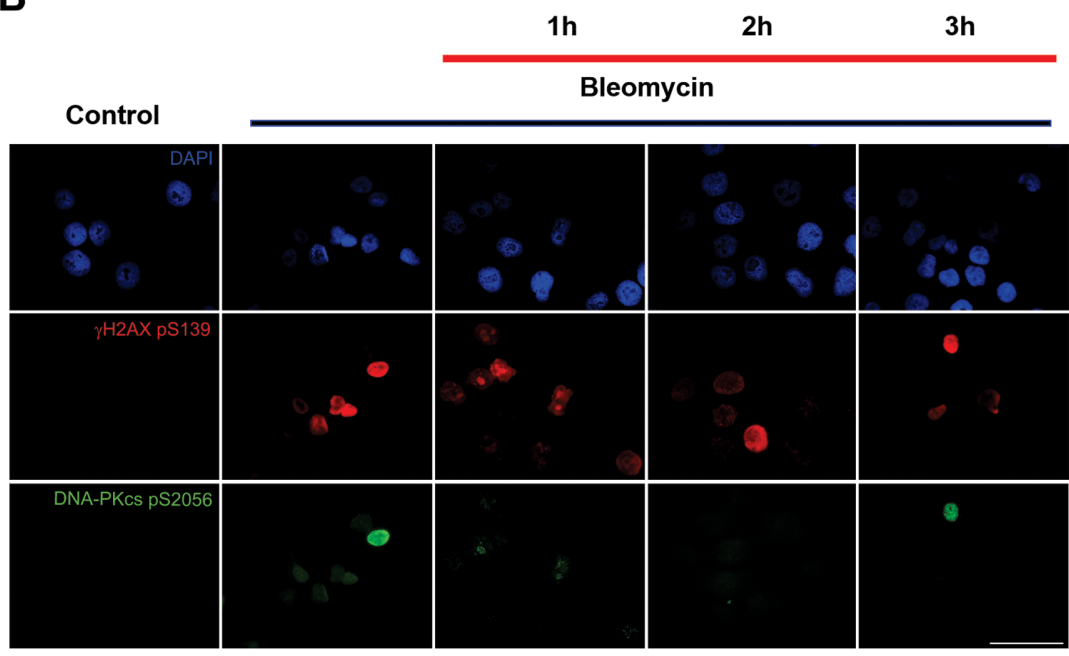

C
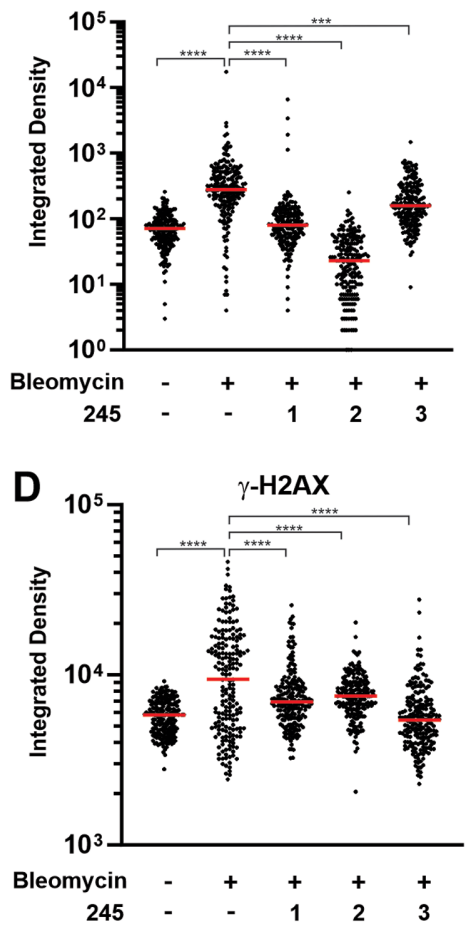

E

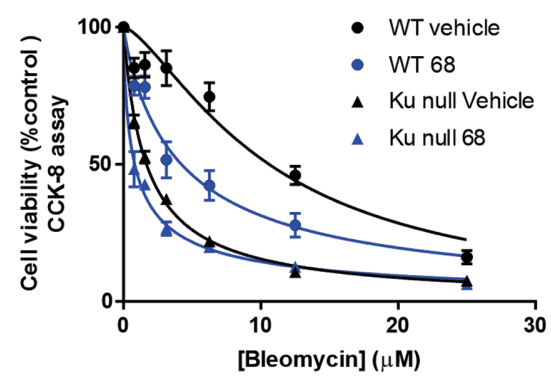

$\mathbf{F}$

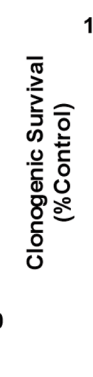

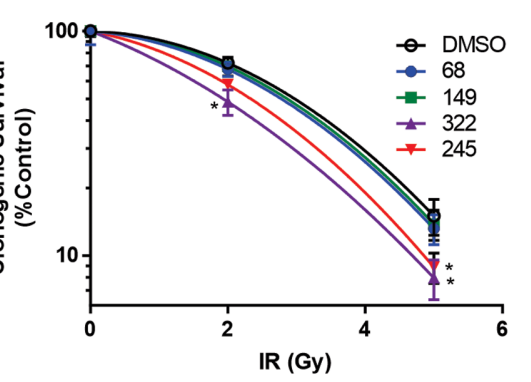

G

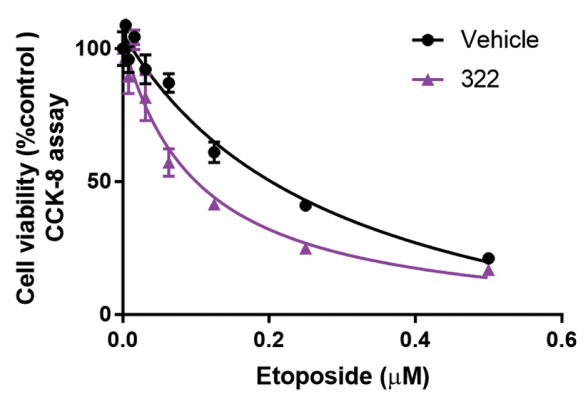

Figure 7. Sensitization to DSB inducing agents by Ku targeted DNA-PK inhibitors. (A) Schematic representation of Bleomycin treatment and $\mathbf{2 4 5}$ preincubation times used in this assay. H460 cells were incubated for 3,2 or $1 \mathrm{~h}$ with $\mathbf{2 4 5}$ inhibitor (indicated in black arrows) and 1-h Bleomycin treatment was applied to each condition (blue line) prior to fixing the cells. (B) Immunofluorescence staining of DNA-PKcs p(S2056) (green) and $\gamma \mathrm{H} 2 \mathrm{~A} . \mathrm{X}$ (pS139) (red) in $\mathrm{H} 460$ cells following treatment. Untreated control cells were incubated with $1 \%$ DMSO. Cells were fixed, immunostained and fluorescence microscopy images were digitally captured using $60 \times$-immersion oil magnification and colored; scale bar: $10 \mu \mathrm{m}$. (C) Quantification of integrated fluorescence intensity of DNA-PKcs p(S2056). (D) Quantification of $\gamma \mathrm{H} 2 \mathrm{AX}$ foci. For (C) and (D) fluorescence microscopy images of $\mathrm{H} 460$ cells subjected to treatments described in (A) were digitally captured using $10 \times$ magnification and analyzed with the extended version Fiji from ImageJ. Data obtained from 200 cells (black circles) are shown as median (red bar). Statistical analysis was determined using unpaired $t$-test; $* * * * P<0.0001 ; * * * P<0.001$. (E) Cellular inhibition of KuDNA interaction by compound 68. MEF cells were seeded and treated with vehicle or $20 \mu \mathrm{M} 68$ and the indicated Bleomycin concentration. Cell viability was assessed by CCK-8 metabolic assay and data are presented as the mean and SEM of triplicate determinations. (F) Enhancement of cell killing after irradiation. After irradiation, cells were plated to assess clonogenic survival as described and data represent the mean and SEM of triplicate determinations. The * denotes points that differ significantly from the DMSO control with a $P<0.05$. (G) Sensitization to etoposide by compound $\mathbf{3 2 2}$. H460 cells were plated and treated with vehicle or $20 \mu \mathrm{M} 322$ and the indicated concentration of etoposide for $48 \mathrm{~h}$ after which cell viability was determined by CCK-8. Data are presented as the mean and SEM of triplicate determinations.

sertion at a DSB created from CRISPR/Cas9 by 6-fold. The data suggest that the increase in recombination efficiency is not necessarily an increase in HDR but a decrease in the inaccurate integration events. These data suggests that $\mathrm{Ku}-$ DBi's could be effective to reduce off-target, potentially mutagenic events that have hampered CRISPR mediated therapeutic applications.

\section{DISCUSSION}

NHEJ is a predominant DSB repair pathway in human cells, and despite the importance of this cellular pathway, many questions regarding the intricacies of the molecular mechanisms driving NHEJ remain. Biochemical and structural studies support a model of DNA-PK activation driven by direct contact with DNA (40-42). The importance of this 
A

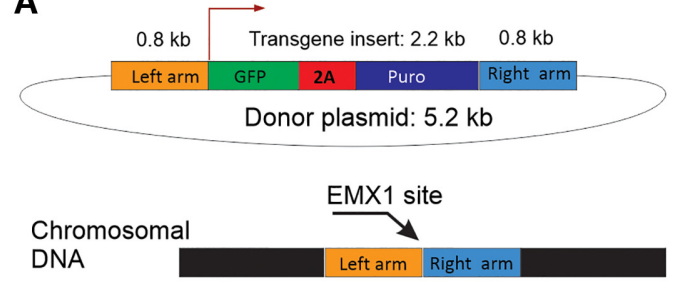

$\downarrow$ Transgene insertion

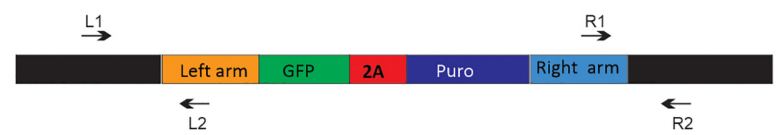

B
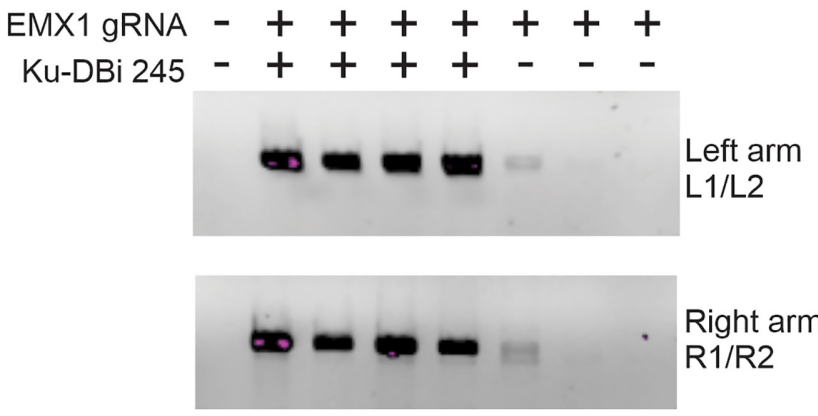

Figure 8. Enhancement of HDR mediated gene insertion. (A) Schematic of gene insertion experiment. The $5.2 \mathrm{kbp}$ donor plasmid was designed with a 2.2 $\mathrm{kb}$ insert to express GFP and confer puromycin resistance. Homology arms of $800 \mathrm{bp}$ were included on either end to target the insertion to the genomic EMX1 site. PCR primers were designed to allow amplification of the left and right junctions to assess accurate gene insertion (B) Genomic DNA was analyzed for precise gene insertion by in/out PCR analysis using the primers depicted in panel (A).

Table 2. Ku-DBi modulation of CRISPR/cas9 mediated gene insertion

\begin{tabular}{lcc}
\hline & Vehicle & Ku-DBi 245 \\
\hline Clones isolated & 28 & 5 \\
PCR positive clones & 4 & 4 \\
Insertion efficiency (\%) & 14 & 80 \\
\hline
\end{tabular}

interaction is evidenced by data demonstrating DNA structure and sequence play a unique and critical role in optimal DNA-PK activation $(20,22)$. Previous work has shown that the $\mathrm{Ku}$ heterodimer is required for efficient NHEJ and functions as a scaffold for other NHEJ proteins to bind including forming a critical interaction with DNA-PKcs (43). In addition, we have previously shown the Ku80 carboxyterminus domain (CTD) plays an important role in DNAPK activation (44). The data presented in this manuscript support the importance of $\mathrm{Ku}$-DNA binding in relation to DNA-PK kinase activity, as direct chemical inhibition of $\mathrm{Ku}-\mathrm{DNA}$ binding activity abolishes kinase activity (Figures 2, 4 and 5). Our demonstration of a direct $\mathrm{Ku}-\mathrm{DBi}$ interaction and the absence of inhibitor binding to DNA confirms the conclusion that our novel small molecule inhibitors bind to the $\mathrm{Ku}$ protein to block the protein-DNA interaction.

Despite advances in understanding DNA-PK biochemical activation, the molecular mechanisms that govern cellular DSB repair pathway choice remain enigmatic. In cells treated with Ku-DBi's, we observe inhibition of DNA-PKcs autophosphorylation at the Ser 2056 cluster (Figure 7), and this results in inhibition of NHEJ catalyzed repair (Figure 6) and an increased cellular sensitivity to a variety of DSB inducing treatments (Figure 7E-G). Having the availability of chemical inhibitors active in cells to target specific steps in the pathways will allow the determination of detailed mechanisms of signaling and repair.

Knowledge of DNA repair pathway enzymology and the mechanisms employed to respond to DNA damage has led to a series of therapeutics that have transformed clinical cancer care. Enhanced DSB repair proficiency is also a major contributor to chemo- and radiotherapy resistance, and blocking DNA-PK dependent repair has been shown to increase sensitivity to various anti-cancer therapeutics. Thus, DNA-PK inhibitors are currently being assessed in combination with chemo- and radiotherapy and as single agents in certain DNA repair deficient cancers. Recent development of more specific and potent inhibitors has resulted in FDA approval to initiate Phase I clinical trials as a potential cancer therapeutic (45). Even with these successes moving forward in the clinic, active site targeted agents have limitations including specificity due to conserved catalytic mechanisms across kinase families, similar structural features of active sites, and the high intracellular ATP concentrations relative to the cellular concentrations of kinase inhibitors. Kinase activity, however, remains only one of the biochemical activities of the DNA-PK complex with binding DNA and supporting protein-protein interaction being integral to its role in repair and DDR. Inhibiting this activity by disrupting the $\mathrm{Ku}-\mathrm{DNA}$ interaction represents a therapeutic avenue that avoids the problems associated with inhibitors targeting the active site of kinases. Results presented here definitively show increased sensitization to the DNA damaging agents Bleomycin, etoposide and IR (Figure 7), and represent a viable class of molecules for both single agent activity and enhancement of the efficacy of DNA damaging agents in the clinic. The unique mechanism of action of Ku-DBi's as DNA-PK inhibitors also suggests that resistance mechanisms are less likely compared to active site targeted kinase inhibitors where resistance is all too common (46). The unique structure of the Ku heterodimer and lack of redundant proteins to compensate for Ku loss portent for an effective therapeutic based on Ku-DBi activity. Analysis of compound specificity revealed that they in fact are highly specific with only a few kinases demonstrating cross-reactivity at high concentrations. One of these kinases, PIM1 is known to play a role in cell cycle progression and apoptosis (33). While is it formally possible that the cellular effect observed is being mediated in part by PIM1 inhibi- 
tion, our data demonstrating that $\mathrm{Ku}$ null cells are insensitive to Ku-DBi's argues against PIM1 inhibition contributing to the observed cellular effects.

The ability to inhibit the initial DNA-binding event is likely to reveal additional complexities associated with double strand break repair pathway choice as having a protein present but inactive at the termini is surely different than not having anything bound to the terminus. Inhibiting the initial molecular event in the NHEJ pathway, $\mathrm{Ku}$ interactions with DNA ends, can efficiently block NHEJ catalyzed repair and is anticipated to drive the processing enzymes to allow HDR-mediated recombination events (36). Demonstration of a switch in pathway choice driven by Ku-DBi's was observed as the efficiency of HDR mediated CRISPR gene insertion of a large donor molecule was increased by 6 -fold as measured by accurate recombination results compared to controls. This result shows that inhibiting $\mathrm{Ku}-\mathrm{DNA}$ binding increases targeting efficiency in genome engineering experiments at least 6-fold over other existing enhancement methods, including chemical inhibition of DNA-PKcs and Ligase IV $(38,39)$. An additional obstacle in the genome engineering field centers around the erroneous nature of NHEJ that results in small insertions and deletions at DNA DSBs in genomic DNA. This is the driving mechanism behind off-target effects observed with engineered nucleases used for precision genome engineering (47). It is well understood that random insertion of a dsDNA molecule, a technique utilized for generating stably transfected cell lines for decades, is driven by NHEJ (47-51). This off-target gene insertion can also result in an increased number of non-edited cells within a larger population of cells that have been treated with CRISPRs, resulting in at times drastically larger number of samples for a researcher to screen or analyze for a cell with a specific edit. Inhibiting NHEJ should decrease these non-specific editing events. The lower number of overall puromycin resistant clonal expansions observed in the $\mathrm{Ku}-\mathrm{DB}$ i treated cells (Table 2) is likely a result of a decrease in off-target insertion of the donor molecule, activity that is typically driven by NHEJ activity. Targeting later steps in the pathway, including DNA-PK kinase activity and ligase IV activity, have been pursued with chemical inhibitors and can reduce NHEJ. Interestingly, multiple groups have also reported negligible effects of the ligase IV inhibitor, SCR7, on genome engineering experiments $(52,53)$, highlighting the need for better, more potent and specific agents that can impact $\mathrm{HDR}$ mediated gene insertion. In general, use of $\mathrm{Ku}-$ DBi's for enhancing genome engineering is applicable to a wide range of cellular model systems. The advantage of targeting $\mathrm{Ku}$ is that the DSB remains unprocessed and eligible for HDR engagement and thus represents a true increase in the number of cells that are capable of HDR activity. Therefore, cells that have not been repaired by NHEJ and have not engaged the HDR system are destined for cell death, resulting in an increased ability to identify and propagate cells with the desired genetically modified sequence.

To date, the only record of an inhibitor targeted to the $\mathrm{Ku}$ protein results from an in silico screen of a commercial library (54) and identifies a core scaffold that may useful in generating new molecules. However, their best compound inhibits only in the mid-micromolar range and its ability to block NHEJ catalyzed DNA DSB repair is not documented to date. In comparison, our core structure is completely different (Figure 1 and Table 1) and our synthetic medicinal chemistry approach has resulted in the synthesis of druglike molecules with high potency and specificity toward $\mathrm{Ku}$ and excellent chemical properties including solubility and stability (data not shown). Studies reported here support a model where the molecules inhibit the $\mathrm{Ku}-\mathrm{DNA}$ interaction by directly binding to the $\mathrm{Ku}$ protein and competitively blocking its association with DNA. Additionally, results in $\mathrm{Ku}$ deficient cells not only validate specificity but also indicate that cellular effects are a function of $\mathrm{Ku}$ inhibition. Together these results support the development of a novel class of molecules that potently inhibit NHEJ through directly disrupting the $\mathrm{Ku}-\mathrm{DNA}$ interaction. The utility of such molecules for both basic science studies as well as therapeutic and commercial development is substantial.

\section{SUPPLEMENTARY DATA}

Supplementary Data are available at NAR Online.

\section{ACKNOWLEDGEMENTS}

The authors thank the IU Simon Comprehensive Cancer Center Chemical Genetics Core Facility and Pat Smith for assistance with flow cytometry.

\section{FUNDING}

National Institutes of Health [R43CA221562, R43GM119880 to K.S.P.; R01 CA247370 to N.S.G., J.J.T.]; American Cancer Society [ACSMRSG-15-163-01 to C.R.S.]; Tom and Julie Wood Family Foundation; NN is supported by NIH training grant T32HL091816. Funding for open access charge: Tom and Julie Wood Family Foundation.

Conflict of interest statement. The authors declare the following competing financial interest(s): J. Turchi is a cofounder and CSO of NERx Biosciences and co-inventor on patents covering the compounds described in this Manuscript.

\section{REFERENCES}

1. Abraham,R.T. (2004) PI 3-kinase related kinases: 'big' players in stress-induced signaling pathways. DNA Repair (Amst.), 3, 883-887.

2. Mohiuddin,I.S. and Kang,M.H. (2019) DNA-PK as an emerging therapeutic target in cancer. Front Oncol., 9, 635

3. Lieber,M.R. (2010) The mechanism of double-strand DNA break repair by the nonhomologous DNA end-joining pathway. Annu. Rev. Biochem., 79, 1-31.

4. Wang,Y., Ghosh,G. and Hendrickson,E.A. (2009) Ku86 represses lethal telomere deletion events in human somatic cells. Proc. Natl. Acad. Sci. U.S.A, 106, 12430-12435.

5. Ruis,B.L., Fattah,K.R. and Hendrickson,E.A. (2008) The catalytic subunit of DNA-dependent protein kinase regulates proliferation, telomere length, and genomic stability in human somatic cells. $\mathrm{Mol}$. Cell Biol., 28, 6182-6195.

6. Sui,J., Zhang,S. and Chen,B.P.C. (2020) DNA-dependent protein kinase in telomere maintenance and protection. Cell Mol. Biol. Lett., 25, 2.

7. Damia,G. (2020) Targeting DNA-PK in cancer. Mutat. Res., 821, 111692 . 
Nucleic Acids Research, 2020, Vol. 48, No. 2011549

8. Goodwin,J.F. and Knudsen,K.E. (2014) Beyond DNA repair: DNA-PK function in cancer. Cancer Discov., 4, 1126-1139.

9. Davidson,D., Amrein,L., Panasci,L. and Aloyz,R. (2013) Small molecules, inhibitors of DNA-PK, targeting DNA repair, and beyond. Front Pharmacol., 4, 5.

10. Stachelek,G.C., Peterson-Roth,E., Liu,Y., Fernandez,R.J. III, Pike,L.R., Qian,J.M., Abriola,L., Hoyer,D., Hungerford,W., Merkel,J. et al. (2015) YU238259 is a novel inhibitor of homology-dependent DNA repair that exhibits synthetic lethality and radiosensitization in repair-deficient tumors. Mol. Cancer Res., 13, 1389-1397.

11. Weber,A.M. and Ryan,A.J. (2015) ATM and ATR as therapeutic targets in cancer. Pharmacol. Ther., 149, 124-138.

12. Ciszewski,W.M., Tavecchio,M., Dastych,J. and Curtin,N.J. (2014) DNA-PK inhibition by NU7441 sensitizes breast cancer cells to ionizing radiation and doxorubicin. Breast Cancer Res. Treat., 143, $47-55$.

13. Furgason,J.M. and Bahassi,e.M. (2013) Targeting DNA repair mechanisms in cancer. Pharmacol. Ther., 137, 298-308.

14. Abuzeid,W.M., Jiang,X., Shi,G., Wang,H., Paulson,D., Araki,K., Jungreis,D., Carney,J., O’Malley,B.W. Jr. and Li,D. (2009) Molecular disruption of RAD50 sensitizes human tumor cells to cisplatin-based chemotherapy. J. Clin. Invest, 119, 1974-1985.

15. Gavande,N.S., VanderVere-Carozza,P.S., Hinshaw,H.D., Jalal,S.I., Sears,C.R., Pawelczak,K.S. and Turchi,J.J. (2016) DNA repair targeted therapy: The past or future of cancer treatment? Pharmacol. Ther. 160, 65-83.

16. Jekimovs,C., Bolderson,E., Suraweera,A., Adams,M., O’Byrne,K.J. and Richard,D.J. (2014) Chemotherapeutic compounds targeting the DNA double-strand break repair pathways: the good, the bad, and the promising. Front Oncol., 4, 86

17. Walker,J.R., Corpina,R.A. and Goldberg,J. (2001) Structure of the $\mathrm{Ku}$ heterodimer bound to DNA and its implications for double-strand break repair. Nature, 412, 607-614.

18. Friesner,R.A., Murphy,R.B., Repasky,M.P., Frye,L.L., Greenwood,J.R., Halgren,T.A., Sanschagrin,P.C. and Mainz,D.T. (2006) Extra precision glide: docking and scoring incorporating a model of hydrophobic enclosure for protein-ligand complexes. $J$. Med. Chem., 49, 6177-6196.

19. Smeaton,M.B., Miller,P.S., Ketner,G. and Hanakahi,L.A. (2007) Small-scale extracts for the study of nucleotide excision repair and non-homologous end joining. Nucleic Acids Res., 35, e152.

20. Pawelczak,K.S. and Turchi,J.J. (2008) A mechanism for DNA-PK activation requiring unique contributions from each strand of a DNA terminus and implications for microhomology-mediated nonhomologous DNA end joining. Nucleic Acids Res. 36, 4022-4031.

21. Gavande,N.S., VanderVere-Carozza,P., Mishra,A.K., Vernon,T.L., Pawelczak,K.S. and Turchi,J.J. (2017) Design and structure-guided development of novel inhibitors of the xeroderma pigmentosum group a (XPA) protein-DNA interaction. J. Med. Chem., 60 , 8055-8070.

22. Pawelczak,K.S., Andrews,B.J. and Turchi,J.J. (2005) Differential activation of DNA-PK based on DNA strand orientation and sequence bias. Nucleic Acids Res., 33, 152-161.

23. Neal,J.A., Sugiman-Marangos,S., VanderVere-Carozza,P., Wagner,M., Turchi,J., Lees-Miller,S.P., Junop,M.S. and Meek,K. (2014) Unraveling the complexities of DNA-dependent protein kinase autophosphorylation. Mol. Cell Biol., 34, 2162-2175.

24. Martinez,M.D., Jafari,R., Ignatushchenko,M., Seki,T., Larsson,E.A., Dan,C., Sreekumar,L., Cao,Y. and Nordlund,P. (2013) Monitoring drug target engagement in cells and tissues using the cellular thermal shift assay. Science, 341, 84-87.

25. Zegzouti,H., Zdanovskaia,M., Hsiao,K. and Goueli,S.A. (2009) ADP-Glo: A Bioluminescent and homogeneous ADP monitoring assay for kinases. Assay. Drug Dev. Technol., 7, 560-572.

26. Nussenzweig,A., Sokol,K., Burgman,P., Li,L. and Li,G.C. (1997) Hypersensitivity of Ku80-deficient cell lines and mice to DNA damage: the effects of ionizing radiation on growth, survival, and development. Proc. Natl. Acad. Sci. U.S.A., 94, 13588-13593.

27. Neher,T.M., Bodenmiller,D., Fitch,R.W., Jalal,S.I. and Turchi,J.J. (2011) Novel irreversible small molecule inhibitors of replication protein A display single-agent activity and synergize with cisplatin. Mol. Cancer Ther., 10, 1796-1806.
28. Sears,C.R. and Turchi,J.J. (2012) Complex cisplatin-double strand break (DSB) lesions directly impair cellular non-homologous end-joining (NHEJ) independent of downstream damage response (DDR) pathways. J. Biol. Chem., 287, 24263-24272.

29. Pawelczak,K.S., Gavande,N.S., VanderVere-Carozza,P.S. and Turchi,J.J. (2018) Modulating DNA repair pathways to improve precision genome engineering. ACS Chem. Biol., 13, 389-396.

30. Scully,R., Panday,A., Elango,R. and Willis,N.A. (2019) DNA double-strand break repair-pathway choice in somatic mammalian cells. Nat. Rev. Mol. Cell Biol., 20, 698-714.

31. Gavande,N.S., VanderVere-Carozza,P.S., Pawelczak,K.S., Vernon,T.L., Jordan,M.R. and Turchi,J.J. (2020) Structure-guided optimization of replication protein A (RPA)-DNA interaction inhibitors. ACS Med. Chem. Lett., 11, 1118-1124.

32. Toure,B.B., Giraldes,J., Smith,T., Sprague,E.R., Wang,Y., Mathieu,S., Chen,Z., Mishina, Y., Feng,Y., Yan-Neale,Y. et al. (2016) Toward the validation of maternal embryonic leucine zipper kinase: discovery, optimization of highly potent and selective inhibitors, and preliminary biology insight. J. Med. Chem., 59, 4711-4723.

33. Haddach,M., Michaux,J., Schwaebe,M.K., Pierre,F., O'Brien,S.E., Borsan,C., Tran,J., Raffaele,N., Ravula,S., Drygin,D. et al. (2012) Discovery of CX-6258. a potent, selective, and orally efficacious pan-Pim kinases inhibitor. ACS Med. Chem. Lett., 3, 135-139.

34. Razmazma,H., Ebrahimi,A. and Hashemi,M. (2020) Structural insights for rational design of new PIM-1 kinase inhibitors based on 3,5-disubstituted indole derivatives: An integrative computational approach. Comput. Biol. Med., 118, 103641.

35. Woods,D.S., Sears,C.R. and Turchi,J.J. (2015) Recognition of DNA Termini by the C-Terminal region of the Ku 80 and the DNA-Dependent protein kinase catalytic subunit. PLoS One, 10, e0127321.

36. Pierce,A.J., Hu,P., Han,M., Ellis,N. and Jasin,M. (2001) Ku DNA end-binding protein modulates homologous repair of double-strand breaks in mammalian cells. Genes Dev., 15, 3237-3242.

37. Ma,Y., Chen,W., Zhang,X., Yu,L., Dong,W., Pan,S., Gao,S., Huang,X. and Zhang,L. (2016) Increasing the efficiency of CRISPR/Cas9-mediated precise genome editing in rats by inhibiting NHEJ and using Cas9 protein. RNA Biol., 13, 605-612.

38. Maruyama,T., Dougan,S.K., Truttmann,M.C., Bilate,A.M., Ingram,J.R. and Ploegh,H.L. (2015) Increasing the efficiency of precise genome editing with CRISPR-Cas9 by inhibition of nonhomologous end joining. Nat. Biotechnol., 33, 538-542.

39. Robert,F., Barbeau,M., Ethier,S., Dostie,J. and Pelletier,J. (2015) Pharmacological inhibition of DNA-PK stimulates Cas9-mediated genome editing. Genome Med., 7, 93.

40. Gupta,S. and Meek,K. (2005) The leucine rich region of DNA-PKcs contributes to its innate DNA affinity. Nucleic Acids Res., 33, 6972-6981.

41. Pawelczak,K.S., Bennett,S.M. and Turchi,J.J. (2011) Coordination of DNA-PK activation and nuclease processing of DNA termini in NHEJ. Antioxid. Redox. Signal., 14, 2531-2543.

42. Serrano-Benitez,A., Cortes-Ledesma,F. and Ruiz,J.F. (2019) "An End to a Means": How DNA-End structure shapes the double-strand break repair process. Front Mol. Biosci., 6, 153.

43. Gell,D. and Jackson,S.P. (1999) Mapping of protein-protein interactions within the DNA-dependent protein kinase complex. Nucleic Acids Res., 27, 3494-3502.

44. Bennett,S.M., Woods,D.S., Pawelczak,K.S. and Turchi,J.J. (2012) Multiple protein-protein interactions within the DNA-PK complex are mediated by the $\mathrm{C}$-terminus of $\mathrm{Ku}$ 80. Int. J. Biochem. Mol. Biol., 3, 36-45.

45. Zenke,F.T., Zimmermann,A., Sirrenberg,C., Dahmen,H., Kirkin,V., Pehl,U., Grombacher,T., Wilm,C., Fuchss,T., Amendt,C. et al. (2020) Pharmacologic inhibitor of DNA-PK, M3814, potentiates radiotherapy and regresses human tumors in mouse models. Mol. Cancer Ther, 19, 1091-1101.

46. Tan,C.S., Kumarakulasinghe,N.B., Huang,Y.Q., Ang,Y.L.E., Choo,J.R., Goh,B.C. and Soo,R.A. (2018) Third generation EGFR TKIs: current data and future directions. Mol. Cancer, 17, 29.

47. Guirouilh-Barbat,J., Huck,S., Bertrand,P., Pirzio,L., Desmaze,C., Sabatier,L. and Lopez,B.S. (2004) Impact of the KU80 pathway on NHEJ-induced genome rearrangements in mammalian cells. Mol. Cell, 14, 611-623. 
48. Bachu,R., Bergareche,I. and Chasin,L.A. (2015) CRISPR-Cas targeted plasmid integration into mammalian cells via non-homologous end joining. Biotechnol. Bioeng., 112, 2154-2162.

49. Ghezraoui,H., Piganeau,M., Renouf,B., Renaud,J.B., Sallmyr,A., Ruis,B., Oh,S., Tomkinson,A.E., Hendrickson,E.A.

Giovannangeli,C. et al. (2014) Chromosomal translocations in human cells are generated by canonical nonhomologous end-joining. Mol. Cell, 55, 829-842.

50. Saito,S., Maeda,R. and Adachi,N. (2017) Dual loss of human POLQ and LIG4 abolishes random integration. Nat. Commun., 8, 16112.

51. Zelensky,A.N., Schimmel,J., Kool,H., Kanaar,R. and Tijsterman,M. (2017) Inactivation of Pol theta and C-NHEJ eliminates off-target integration of exogenous DNA. Nat. Commun., 8, 66.
52. Yang,D., Scavuzzo,M.A., Chmielowiec,J., Sharp,R., Bajic,A. and Borowiak,M. (2016) Enrichment of G2/M cell cycle phase in human pluripotent stem cells enhances HDR-mediated gene repair with customizable endonucleases. Sci. Rep., 6, 21264.

53. Zhang,J.P., Li,X.L., Li,G.H., Chen,W., Arakaki,C., Botimer,G.D., Baylink,D., Zhang,L., Wen,W., Fu,Y.W. et al. (2017) Efficient precise knockin with a double cut HDR donor after

CRISPR/Cas9-mediated double-stranded DNA cleavage. Genome Biol., 18, 35.

54. Weterings,E., Gallegos,A.C., Dominick,L.N., Cooke,L.S., Bartels,T.N., Vagner,J., Matsunaga,T.O. and Mahadevan,D. (2016) novel smallmolecule inhibitor of the DNA repair protein $\mathrm{Ku} 70 / 80$. DNA Repair (Amst), 43, 98-106. 